\title{
Direct and Indirect Costs of Non-surgical Treatment for Acute Tonsillitis in Children in Southeast Nigeria
}

\author{
Maduka Donatus Ughasoro ${ }^{1,2}$. James Onuorah Akpeh ${ }^{3}$. Nneamaka Echendu ${ }^{2}$. Somkene Okpala ${ }^{2}$. \\ Nneka Getrude Mgbachi ${ }^{4}$. Ogochukwu Chinelo Okanya ${ }^{5}$. Obinna Emmanuel Onwujekwe ${ }^{6}$
}

Accepted: 22 January 2021 / Published online: 8 April 2021

(c) The Author(s) 2021

\begin{abstract}
Background Acute tonsillitis has become one of the main reasons why children visit healthcare facilities in Nigeria. Presently, there is no information on the costs of its treatment, and this study aimed at determining these costs.

Methods The study was conducted in two hospitals located in southeast Nigeria. The information was obtained in two ways: (1) retrospectively from the medical records of children treated for acute tonsillitis over a period of 5 years and (2) cross-sectionally from children who presented with complaints of acute tonsillitis over a period of 7 months. The information obtained was the costs of self-medication and hospital treatment, and the payment mechanisms used to settle these costs. The human capital method approach was used to estimate the indirect cost (loss in productivity) from the caregivers' absenteeism from work.

Results The mean costs of self-medication and hospital treatment for acute tonsillitis in children were $€ 3.85$ and $€ 13.48$, respectively. The indirect cost was $€ 11.31$. The mean total cost of treatment of acute tonsillitis was $€ 23.80$. The proportion of households that suffered catastrophic health expenditure (CHE) from the treatment of acute tonsillitis was 55 (55\%). CHE was highest [22 (91.7\%)] in the lowest socio-economic quartile compared to households in the highest quartile [4 (16.7\%)], and the difference was statistically significant $(p=0.02)$. Of the 72 participants whose payment mechanisms were documented, the proportion who paid out of pocket was 53 (73.6\%), and 19 (26.4\%) used the National Health Insurance Scheme. Conclusion The costs of treatment for children with acute tonsillitis were high, and most of these costs were settled out-ofpocket. The costs for laboratory investigations, drugs, and productivity loss contributed to these high costs. There is a need to cover the costs of non-surgical treatment of acute tonsillitis in social health insurance and improve efforts to increase the coverage of the health insurance scheme.
\end{abstract}

\section{Introduction}

James Onuorah Akpeh

james.akpeh@unn.edu.ng

1 Department of Paediatrics, University of Nigeria Enugu Campus, Enugu, Nigeria

2 Department of Paediatrics, University of Nigeria Teaching Hospital, Ituku/Ozalla, Enugu, Nigeria

3 Department of Otorhinolaryngology, University of Nigeria Enugu-Campus, Enugu, Nigeria

4 Department of Microbiology, University of Nigeria Teaching Hospital, Ituku/Ozalla, Enugu, Nigeria

5 Department of Banking and Finance, Institute of Management and Technology, Enugu, Nigeria

6 Health Policy Research Group, University of Nigeria Enugu Campus, Enugu-Campus, Enugu, Nigeria
Acute tonsillitis is an extensive inflammation of oropharyngeal lymph nodes, which are situated in the upper respiratory tract $[1,2]$. Acute tonsillitis in children has become one of the reasons for visits to the healthcare facilities in Nigeria [3, 4]. Adoga et al. [4], in their study of otolaryngology emergencies in Nigeria, reported $63.5 \%$ were paediatric emergencies, among these emergency cases, $73.6 \%$ were children under 5 years of age. Nigeria has a teeming population of children below 5 years of age, estimated at 31 million [5], which highlights the burden of acute tonsillitis in Nigeria. Although the prevalence of acute tonsillitis among Nigerian children has not been documented, but if the prevalence $11 \%$ that was documented in Ethiopia [6], is to be extrapolated to the Nigerian with a population of children under 5 years of 31 million [7], at least 3.4 million cases of acute tonsillitis would be reported annually [7]. This would be even much 


\section{Key Points for Decision Makers}

The mean cost of treatment was high and adversely affected the welfare of most households who sought care for a child with acute tonsillitis, especially poor households. These costs can be reduced if evidence-based practice is observed.

The lost in productivity of the parents/caregivers of these children associated with treatment for acute tonsillitis was high. This can be reduced if the time spent in the hospital is reduced such that parents/caregivers can still return to work the day they brought their children to the hospital.

There was high incidence of out-of-pocket spending in the payment of treatment costs. The proportion of respondents that used any form of social health insurance to pay for treatment of acute tonsillitis was very small.

higher if recurrent episodes of acute tonsillitis were to be considered also [8].

Conventionally, most cases of acute tonsillitis deserve some form of treatment. The treatment can vary and may include symptomatic relief remedies with analgesics, use of appropriate antibiotics (especially in cases of streptococci infection and/or peritonsillar abscess $[9,10]$ ), and tonsillectomy, which is the surgical removal of the tonsils, especially in recurrent cases and patients with obstructive sleep apnoea [11-14]. These treatments for acute tonsilitis can commence as self-medication at home, medical treatment at the healthcare facility, or surgical intervention. The commonest among these interventions is medical care either at home or a hospital, and each has its cost implications, which are yet to be evaluated in resource poor countries like Nigeria. The information on the cost implications of these interventions is very relevant, especially in countries and regions where self-medication is practiced and the liberal use of antibiotics is high [15]. The economic cost of treatment for acute tonsillitis is likely to be a huge proportion of household and state budgets and expenditures, and deserves to be investigated, especially in settings like Nigeria, where there is a large number of children at risk of acute tonsillitis and many households are living below the poverty line.

An extensive literature search revealed that studies that had evaluated the economic cost of treatment for acute tonsillitis were either conducted in developed countries with different cost structures compared to developing countries like Nigeria $[16,17]$ or summed the cost of the surgical and medical treatment [18-20] or combined the populations of children and adults in one study [21]. Leupe et al.
[16] and Duarte et al. [17] in their study of children in developed countries reported a higher cost of treatment for acute tonsilitis, a many hospital visits, and average of 2.1 prescription fills annually in children with acute tonsillitis more when compared to children without acute tonsillitis $(p<0.001)$. Chang et al. [18] and Wilson et al. [19] focused on the cost-effectiveness of surgical treatment of chronic adenotonsillar hypertrophy in children. Gudnadottir et al. [20] studied only the indirect cost of paediatric tonsil surgery due to caregivers' absence from work. Roos et al. [21] estimated the economic cost of a streptococcal tonsillitis episode in both children and adults. There has been no study on the economic cost of acute tonsillitis in Nigeria or in Sub-Saharan Africa, but a study by Suleiman and Tayo [22] has evaluated the cost of ear, nose, and throat infections together.

Information on the cost of treatment of acute tonsillitis will be relevant in developing countries like Nigeria. It will be a useful advocacy tool in policy reform and will help in the design of an intervention programme, especially with the growth in interest on how to improve universal health coverage (UHC) through social health insurance: formal sector health insurance [23] and community-based health insurance schemes (CBHISs) [24]. The evidence from this study will form a guide on reimbursement packages and fee setting for healthcare providers for their services in order to ensure equity and sustainability $[25,26]$.

This study was set to determine the economic cost of treatment for childhood acute tonsillitis in a resource-poor setting, considering both the cost of self-medication and that of health facility care. The costs were reviewed under the following categories: cost of transportation, cost of consultation, cost of investigations, cost of drugs, and the indirect cost of parents' and caregivers' absenteeism from work. The inclusion of cost of self-medication in this study was innovative, especially in Nigeria where the practice of selfmedication is very high as in other countries where there are liberal use of broad-spectrum antibiotics [27, 28].

\section{Methods}

\subsection{Study Area}

The study took place in two tertiary hospitals: the University of Nigeria Teaching Hospital (UNTH), Ituku-Ozalla, in Enugu State, and the Federal Medical Center (FMC), Umuahia, in Abia State. The two states are located in the southeastern part of Nigeria. The UNTH is located in the rural area of Nkanu West local government area (LGA), which has a population of 146,695 [29], while the FMC is located in the urban area of Umuahia North LGA with a population of 359,230 [30]. The population densities of Nkanu West 
and Umuahia North LGAs were 923.8 persons $/ \mathrm{km}^{2}$ and 1138 persons $/ \mathrm{km}^{2}$, respectively $[29,30]$. The Nkanu West area is a mixture of semi-urban and rural communities, while Umuahia North is a mixture of both urban, semi-urban, and rural communities. Both hospitals provide different speciality services (paediatrics, internal medicine, surgery, obstetrics and gynaecology, laboratory medicine, etc.) to patients from both within and outside their states. The hospitals are government owned, and fee-for-service and health insurance payment mechanisms were available in both facilities. There were good laboratory and pharmaceutical services in both hospitals.

The paediatric departments of the hospitals provide both out-patient and in-patient care. There are consultants, resident doctors, house officers, nurses, and pharmacists working in different units. An average of 210 and 245 children present to the paediatric out-patient clinics with acute tonsillitis annually in the UNTH and FMC, respectively. Children who present to the out-patient clinics with febrile illnesses are often placed on treatment, which may include use of antibiotics.

\subsection{Study Design}

The study combined retrospective and cross-sectional approaches.

\subsubsection{Retrospective Approach}

The medical records of children treated for acute tonsillitis from 2015 to 2019 were reviewed. The essence of the retrospective approach was to obtain the variation in prescribed treatments and investigations from different healthcare providers that managed the patients over different periods of time. This approach removed the bias in treatment approach that might occur when healthcare providers managed patients recruited for research.

\subsubsection{The Cross-Sectional Approach}

This approach was essentially to obtain all the required information, including the payment mechanisms used by caregivers to settle hospital bills. Information on the payment mechanism is not routinely documented in the medical records of patients.

\subsection{Sampling and Sample Size}

The sample size calculation was based on a prevalence rate of childhood tonsillitis of $11 \%$ [6] and the $95 \%$ confidence interval, and a power of $80 \%$ and a minimum sample size of 140 children within the age range of 6 months to 17 years with acute tonsillitis were obtained. The literature search at the time the study was conducted did not find any Nigerian study on the prevalence of acute tonsillitis in children for the calculation of sample size. The sample size was divided into two; 100 medical records of children treated for acute tonsillitis were reviewed in the retrospective part of the study, while 72 children that presented at the clinic with enlarged, inflamed, tonsils, and/or tonsillar exudate were recruited in the cross-sectional part of the study. These were summed up to 172 participants.

More relevant data and throat swabs were taken from 44 children who presented to the children's outpatient clinics of the two study hospitals with acute illnesses other than acute tonsillitis. This was done to document and compare the common microbial isolates of children with acute tonsillitis and the group without inflamed tonsils, as well as to understand the predisposing effect of age and place of residence on acute tonsillitis.

\subsection{Data Collection}

\subsubsection{Primary Data}

A total of 1020 and 1225 children were managed for acute tonsillitis in the children's out-patient clinics of the UNTH and FMC, respectively, over the 5-year period from January 2015 to December 2019. The medical records of these children were listed and numbered. A total of 100 medical records were selected from the list using simple random sampling. Selection was based on documentation of treatment and investigations on the patient's medical record. If the selected record could not be traced or could be traced but lacked documentation of minimum information, the record was not captured, but rather the next on the list was selected until the desired number was obtained. Information on patient age, gender, place of residence, parents'/caregivers' occupations, household size, presenting symptoms, health seeking behaviours, and treatment received was documented in a case report form.

Furthermore, children with enlarged, inflamed tonsils and tonsillar exudate who presented to children's out-patient clinics from March 2019 to September 2019 were consecutively selected. Throat swabs were taken for microscopy, culture, and sensitivity. Other information obtained included the time of arrival to the hospital and the time the patient was seen by a doctor, the payment mechanism(s) used, the patient's household expenditure on food, cooking fuels, electricity, and generator fuel, and ownership of household items. A table of the weighted indices of these items according to Karigi [31] was used in the generation of a wealth index using principal component analysis [32]. See Table 1. 


\subsubsection{Secondary Data}

The costs estimated were grouped into three categories: self-medication, treatment in health facility, and caregivers' productivity loss.

\subsubsection{Cost of Self-Medication and Health Facility-Based} Treatment (Direct Cost) Information on patients' health seeking behaviour before presenting to the facilities was obtained from a review of the medical records of children managed for acute tonsillitis, as well as a direct history obtained from the patient at presentation. The costs of transportation, laboratory investigations, and drug usage were obtained, and what had been spent to receive such services was either estimated or directly obtained from the respondents. Information on the patients' health facility-based treatment, which included transportation cost, laboratory investigations, consultation fee, and drugs prescribed, was also obtained.

2.4.2.2 Loss in Productivity (Indirect Cost) The indirect costs were estimated from the daily income loss of the parents/caregivers based on the period they were absent from work to enable them take their children to the clinics, depending on their occupations, using the human capital approach [33]. The time of day the child was seen by a doctor in the hospital was documented. It was assumed that parents/caregivers who stayed in the hospital beyond midday did not return to work later that day, and these instances were counted as 1 day out of work. In this approach, the estimate was based on the assumption that the time lost from work related to a child with acute tonsillitis can be equated to the earnings lost during that period. The societal cost is a summation of private and external costs. There was no significant external cost of treatment of acute tonsillitis in children. The external cost of acute tonsillitis was the cost borne by co-workers or partners in business when caregivers are absent from work. However, the period caregiver were absent from work were too short in duration to cause any significant change in the dynamics of the work environment-i.e. none that would warrant new employment or a reduction in production or sales. The cost of obtaining a babysitter to take care of the home while parents/caregivers took their children to hospital would have been another external cost. However, in the Nigerian context, most parents have babysitters or housemaids, and even families that do not, parents of such families often take their babies along with them while visiting hospitals. It is only in situations where the children are on hospital admission for a prolonged period of time that external help are often solicited. But such was not the case in the management of acute tonsillitis.

Only private costs from loss of income were estimated. The varied estimates of daily income losses were generated from different occupations obtained in a survey [34]. Unemployed parents, petty traders, students, transporters using a motorcycle, and labourers were assigned $€ 3.27$ income per day, according to the Nigerian minimum wage of $€ 65.45$ per month; commercial drivers and civil servants were assigned $€ 10.75$; workers in the private sector and self-employed professionals were assigned $€ 14.22$; while those working in medium and large businesses were assigned $€ 34.12$.

Table 1 Weighted wealth index

\begin{tabular}{llll}
\hline Household items & Weighted values & Household items & Weighted values \\
\hline Source of water & & Building materials & \\
Water source piped into dwelling & 0.354 & Roofing tiles & 0.343 \\
Water source piped to yard & 0.285 & Straw & 0.04 \\
Public tap & 0.055 & Cooking fuel & \\
Borehole & 0.026 & Gas & 0.032 \\
Protected well & 0.084 & Kerosene & 0.156 \\
Unprotected well & 0.057 & Wood & 0.64 \\
Unprotected spring & 0.106 & Charcoal & 0.364 \\
Rain & 0.141 & Equipment & \\
Tanker truck supply & 0.232 & Radio & 0.357 \\
Human waste management & & Television & 0.668 \\
Water cistern flushed to central sewage & 0.27 & Refrigerator & 0.69 \\
Pit latrine & 0.162 & Bicycle & 0.142 \\
Bush & 0.351 & Motorcycle & 0.17 \\
Bucket & 0.016 & Motorcar & 0.627 \\
\hline
\end{tabular}

Taken from Karigi 2014 [31] 


\subsection{Data Analysis}

The data were entered and analyzed using SPSS version 22 . The direct cost was based on the cost of consultation, drugs, laboratory investigations, and transportation. The standard hospital charges for a hospital consultation and laboratory investigations were used for the cost estimation. The cost of transportation was based on the distance between the patient's residence and the hospital. Since the majority of patients procured their medications from pharmacies outside the hospital, the average market prices for the different drugs taken by these children obtained through a market survey were used when the caregiver could not provide such information. An estimated dosage based on the patient's weight was used to determine the amount of the drug taken and the cost if that quantity was to be purchased. If the total dosage the child required was more than the dosage in one unit/ bottle of the drug, the summed cost of the number of units/ bottles that contained the total dosage was used as the cost of treatment, not minding that some quantity may remain unused in the last unit purchased. This has to be done since paediatric syrups and parenteral medications are not sold in aliquots but in a whole unit or bottle.

The indirect cost, i.e. the loss in productivity, was estimated based on work absenteeism based on 1 day of lost productivity being equivalent to 1 day of salary/wages plus social costs [20]. The information on the average income for each occupation was estimated through a public survey, and the average was obtained and compared with the findings of Ughasoro et al. [34]. All cost estimates were computed in the Nigerian currency, Naira $(\mathrm{N})$, and converted to European Euros $(€)$ using a 2019 exchange rate of N422 to $€ 1$.

Population density is the measurement of the number of people living in a land area per square kilometre excluding the area occupied by water. Population density is classified into extremely low density $\left(\leq 100 / \mathrm{km}^{2}\right)$, low density $\left(101-250 / \mathrm{km}^{2}\right)$, moderate/medium density (251-500/ $\mathrm{km}^{2}$ ), high density $\left(501-1000 / \mathrm{km}^{2}\right)$, and very high density $\left(>1000 / \mathrm{km}^{2}\right)$ [35]. In this study, the participants' areas of residence were used to determine the population density of their place of residence.

A wealth index based on the household items was used to group the participants into quartiles of lowest, second, third, and highest using a principal component analysis. Catastrophic health expenditure (CHE) was calculated based on health expenditure being more than $40 \%$ of non-food expenditure incurred monthly [36, 37].

Frequencies were calculated. The Shapiro-Wilk $W$ test was used to test for normality (normal distribution) of the data. The data had a normal distribution, justifying the use of means. The Chi-squared test was used to test for significant differences. A $p$ value of less than or equal to 0.05 was taken to be significant. Fisher's exact test was used for variables with a value of less than 5 [38]. The time interval between when the patient arrived at the hospital and when they were seen by a doctor was documented as the time spent in the hospital (in hours).

\subsection{Ethical Consideration}

Approval to conduct this study was obtained from the Health Research and Ethics Committee of UNTH, ItukuOzalla. The obtained ethical approval and the proposal were presented to the Health Research and Ethics Committee of the FMC, Umuahia, for review and approval to conduct the study. Written informed consent was obtained from the parents/caregivers before recruiting their children into the study.

\section{Results}

The weighted wealth index of different household items and building facilities was based on the estimations of Karigi in his 2014 [31] report (see Table 1).

The proportion of children with acute tonsillitis that resided in medium- and high-density areas was significantly higher $(141 ; 82 \%)$ than that for those who presented with other common childhood illnesses $(34 ; 77.2 \%), p$ value $=0.021$ (see Table 2$)$.

The medical records of 100 participants were reviewed, and 39 (39\%) did the requested investigation, 35 (35\%) did not do the requested investigation, while $26(26 \%)$ had no laboratory investigation requested. Among the 72 participants who had their payment mechanisms determined, $53(73.7 \%)$ used out-of-pocket (OOP) payment, compared to $19(26.4 \%)$ that used the National Health Insurance Scheme (NHIS). The mean cost of self-medication was $€ 3.85$. The mean direct hospital cost of treatment for acute tonsillitis was $€ 13.48$. The mean loss of productivity of parents/ caregivers was $€ 11.31$. The mean total cost of treatment of acute tonsillitis in children was $€ 23.80$. The mean household non-food expenditure was $€ 28.86$. The proportion of the participants that experienced CHE was 55 (55\%) (see Table 3).

The CHE was higher among the lowest quartile (22; $91.7 \%)$ compared to the highest $(4 ; 16.7 \%)$, and the difference was statistically significant $(p=0.02)$ (see Table 4$)$.

\section{Discussion}

According to this study, most of the children with acute tonsillitis reside in a high-density area. There is this assumption that children living in densely populated areas are predisposed to respiratory infections as a result of exposure to air 
Table 2 The sociodemographic characteristics of children with acute tonsillitis and other acute illnesses

\begin{tabular}{|c|c|c|c|c|}
\hline Variables & $\begin{array}{l}\text { Acute tonsillitis } \\
(n=172)\end{array}$ & $\begin{array}{l}\text { Other acute ill- } \\
\text { nesses }(n=44)\end{array}$ & $\chi^{2}$ & $p$ value \\
\hline \multicolumn{5}{|l|}{ Gender } \\
\hline Male & $91(52.9 \%)$ & $17(38.6 \%)$ & \multirow[t]{2}{*}{2.854} & \multirow[t]{2}{*}{0.0911} \\
\hline Female & $81(47.1 \%)$ & $27(61.4 \%)$ & & \\
\hline \multicolumn{5}{|l|}{ Age } \\
\hline$\leq 1$ years & $38(22.1 \%)$ & $7(15.9 \%)$ & \multirow[t]{5}{*}{26.41} & \multirow[t]{5}{*}{0.000026} \\
\hline$>1$ to $\leq 3$ years & $76(44.2 \%)$ & $7(15.9 \%)$ & & \\
\hline$>3$ to $\leq 5$ years & $27(15.7 \%)$ & $6(13.6 \%)$ & & \\
\hline$>5$ to $\leq 10$ years & $15(8.7 \%)$ & $12(27.3 \%)$ & & \\
\hline$>10$ years & $16(9.3 \%)$ & $12(27.3 \%)$ & & \\
\hline \multicolumn{5}{|l|}{ Household size (persons) } \\
\hline Mean \pm SD & $4.4(1.8)$ & $5.3(1.5)$ & & \\
\hline Median & 4 & 5 & & \\
\hline Range & $3-8$ & $3-8$ & & \\
\hline \multicolumn{5}{|l|}{ Place of residence } \\
\hline Low-density area & $23(13.4 \%)$ & $2(4.6 \%)$ & \multirow[t]{4}{*}{7.773} & \multirow[t]{4}{*}{0.021} \\
\hline Medium-density area & $86(50 \%)$ & $28(63.6 \%)$ & & \\
\hline High-density area & $55(32 \%)$ & $6(13.6 \%)$ & & \\
\hline Outside the study area & $8(4.6 \%)$ & $8(18.2 \%)$ & & \\
\hline \multicolumn{5}{|c|}{$\begin{array}{l}\text { Time of the day the patient was seen by a } \\
\text { doctor at hospital visit ( } 24 \mathrm{~h} \text { timing) }\end{array}$} \\
\hline Mean & 12.28 p.m. & 12.30 p.m. & & \\
\hline Median & 12 noon & 12.10 p.m. & & \\
\hline \multicolumn{5}{|c|}{ Mothers' occupation $(n=144)$} \\
\hline Civil servant & $45(31.3 \%)$ & & & \\
\hline Business & $25(17.4 \%)$ & & & \\
\hline Housewife/unemployed & $23(16 \%)$ & & & \\
\hline Teacher & $19(13.2 \%)$ & & & \\
\hline Nurse & $7(4.8 \%)$ & & & \\
\hline Petty trader & $4(2.8 \%)$ & & & \\
\hline Others & $21(14.5 \%)$ & & & \\
\hline
\end{tabular}

pollutants and an increased risk of invasion by pathogenic bacteria. Unfortunately, there was no study that evaluated the prevalence of respiratory infections and the level of population density in the area of residents. However, Lupatsch et al. [39] have reported that neighbourhood child density was a poor proxy for exposure to infections in infancy.

There was poor compliance with requested investigations and treatment based on investigation results. In this study, a full blood count investigation was requested in $74 \%$ of the participants and 39\% received treatment based on the investigation results. Unfortunately, previous focus on compliance and non-compliance has been on prescribed treatment [40, 41] and has been often interchangeable with adherence [42]. Understanding that non-compliance extends to requested investigations will be relevant with respect to the formulation of an efficient strategic intervention in healthcare [40] and cost savings in the long run [43, 44]. In this era of confirmation before treatment and evaluation of cost-effective treatment alternatives in healthcare delivery [45], any factor that contributes to an increase in the efficiency of a treatment plan is of importance to healthcare providers.

The cost of treatment of tonsillitis was high for the average household, and much higher costs of $€ 1048$ and $€ 1106.8 \pm 331.3$ (US1303 \pm 390$)$ have been reported by Leupe et al. [16] and Duarte et al. [17], respectively. The costs of drugs and laboratory investigations were the highest contributors to the medical cost of treatment of tonsillitis. This is similar to the results of a study by Suleiman and Tayo [22] in Nigeria, in which antibacterial cost constituted the highest cost component $(64.3 \%)$ of the cost of treatment of ear, nose, and throat infection per patient. This cost can be reduced where evidence-based practice is being observed. The National Associations of Otolaryngologists recommended systemic antibacterial therapy as the most appropriate treatment in complicated tonsillitis, e.g. abscess, and/or evidence of streptococcal aetiology in the 
Table 3 Cost of treatment for children with acute tonsillitis

\begin{tabular}{lll}
\hline Variables & $n(\%)$ & Average \\
\hline Previous episodes of tonsillitis $(n=172)$ & $24(14 \%)$ & \\
Yes & $148(86 \%)$ & \\
No & $39(39 \%)$ & \\
Full blood count $(n=100)$ & $35(35 \%)$ & \\
Requested and done (treated with investigation result) & $26(26 \%)$ & $€ 3.85$ \\
Requested but not done & & \\
Not requested & $53(73.6 \%)$ & $19(26.4 \%)$ \\
Payment mechanism ( $n=72)$ & & $€ 13.48$ \\
Out-of-pocket & & $€ 1.69$ \\
NHIS & & $€ 6.73$ \\
Cost of treatment of tonsillitis & & $€ 14.19$ \\
Mean direct cost of health seeking prior to hospital visit (self- & & $€ 11.31$ \\
medication) & & $€ 23.80$ \\
Mean direct cost of hospital care for tonsillitis & & $€ 28.86$ \\
Mean cost of transportation & & \\
Mean cost of registration/consultation & & \\
Mean cost of laboratory investigation & & \\
Mean cost of drug & & \\
Mean loss of productivity by parents/caregivers & & \\
Mean total cost of treatment of childhood tonsillitis & & \\
Mean household non-food expenditure & & \\
Catastrophic health expenditure & & \\
\hline
\end{tabular}

NHIS National Health Insurance Scheme

Table 4 Catastrophic health expenditure effect of treatment of acute tonsillitis on different socio-economic quartiles

\begin{tabular}{llllll}
\hline $\begin{array}{l}\text { Catastrophic health } \\
\text { expenditure }(n=100)\end{array}$ & Lowest $(n=24)$ & Second $(n=27)$ & Third $(n=25)$ & Highest $(n=24)$ & $\chi^{2}$ \\
\hline Yes & $22(91.7 \%)$ & $23(85.2 \%)$ & $6(24 \%)$ & $4(16.7 \%)$ & 9.93 \\
No & $2(8.3 \%)$ & $4(14.8 \%)$ & $19(76 \%)$ & $20(83.3 \%)$ & 0.02 \\
\hline
\end{tabular}

inflammatory process [46]. Unfortunately, antibiotic usage remained unregulated, from home treatment to facility treatment. In this study, €3.85 was spent on treatments taken before visiting a hospital. Duarte et al. [17] in their study of children in USA reported children with acute tonsillitis incurred average of 2.1 more prescription fills $(p<0.001)$ annually when compared with those children without acute tonsillitis. There was no study that evaluated the medical cost of treatment of tonsillitis, except Chang et al.'s [18] study that reported a high surgical cost for tonsillectomy ( $€ 1129.8$; US\$1228). Despite the high cost of tonsillectomy, when compared to the cost of medical treatment of acute tonsillitis, it could be cost saving. Wilson et al. [19] in their randomized clinical trial revealed that tonsillectomy when promptly done saved up to eight episodes of sore throats.

The majority $(55 \%)$ of the households experienced CHE, when a threshold of $40 \%$ of monthly non-food expenditure was used and this CHE occured in $91.7 \%$ of the poorest/ lowest and $16.7 \%$ of the highest/richest households. A similar pattern has been documented [46] before. The incidence of $\mathrm{CHE}$ is worse in any place where the utilization of prepayment plans like national health insurance is very low and there is a high reliance on OOP, as indicated in this study. The three principal pre-conditions (availability of health services that need payment, low capacity to pay, and a lack of health financial risk pooling) that predispose people to $\mathrm{CHE}$ according to $\mathrm{Xu}$ et al. [37] were very much present in this study. The NHIS was inaugurated in Nigeria more than a decade ago $[47,48]$, and it has not performed well with regard to the provision of financial risk protection for the population [49].

In this study, OOP was $73.6 \%$, and other studies have reported even higher percentages [34, 50]. Households in developed countries are protected from $\mathrm{CHE}$ by adequate health insurance coverage or a tax-funded health system with adequate subsidies. In developing countries, however, high 
OOP payments, an absence of risk-pooling mechanisms in health financing systems, and a high level of poverty can cause CHE [51]. Access to UHC will not be feasible in a community where the OOP payment for healthcare is over $30 \%$ of the total spending on healthcare [52]. This highlights the need to expand the coverage of social health insurance; introducing community-based health insurance is one sure way to achieve this, especially in communities where less than $10 \%$ are employed in the formal sector that the current NHIS covers.

\section{Limitations}

This study has some limitations that may need to be addressed in subsequent studies. The exclusion of the cost of surgery for patients that had adenotonsillectomies is one. Although the study focused on acute tonsillitis, indications and reasons for surgery were often recurrent episodes of acute tonsillitis and complications like obstructive sleep apnoea. Although the inclusion of the cost of surgery and its follow-up would amount to a high average cost, such information is necessary for decision and policy reforms. Another limitation of the study was the use of weighted wealth indices from another country rather than indigenous Nigerian weighted wealth indices. It was unfortunate that there were no published wealth indices from Nigeria. This is an opportunity for future study.

\section{Conclusion}

The costs of treatment for children with acute tonsillitis were high, and most of these payments were settled OOP. The costs for drugs and productivity loss contributed to these high costs. There is a need to cover the costs of non-surgical treatment of acute tonsillitis in social health insurance, and efforts should also be made to improve coverage of the health insurance scheme.

Acknowledgements We would like to thank all parents that allowed their children to participate in this study. We also want to thank University of Nigeria Nsukka that sponsored the publication fee for this manuscript.

\section{Declarations}

Funding The study was funded by Tertiary Educational Trust Fund (TETFund) received through the University of Nigeria, Nsukka.

Ethics approval The study protocol was approved by the University of Nigeria Teaching Hospital, Health Research Ethics Committee.

Consent to participate Written informed consent was obtained from all participants involved in the study.
Consent for publication Not applicable.

Availability of data and material More complete data are available from the authors upon request.

Code availability Not applicable.

Conflict of interest The authors have no conflicts of interest to declare.

Author Contributions MDU and JOA conceptualized and designed the study and ensured its overall coordination. MDU and OCO developed and reviewed study tools. NE, SO, and NGM were responsible for the overall data collection and laboratory investigations. OEO gave technical and economic evaluation guidance throughout the study. MDU and OCO were responsible for data management and analysis. The manuscript was drafted by MDU and JOA. All authors made critical comments on the manuscript draft and approved the final version of the manuscript for submission and agreed to be responsible for all aspects of the work.

Open Access This article is licensed under a Creative Commons Attribution-NonCommercial 4.0 International License, which permits any non-commercial use, sharing, adaptation, distribution and reproduction in any medium or format, as long as you give appropriate credit to the original author(s) and the source, provide a link to the Creative Commons licence, and indicate if changes were made. The images or other third party material in this article are included in the article's Creative Commons licence, unless indicated otherwise in a credit line to the material. If material is not included in the article's Creative Commons licence and your intended use is not permitted by statutory regulation or exceeds the permitted use, you will need to obtain permission directly from the copyright holder. To view a copy of this licence, visit http://creativecommons.org/licenses/by-nc/4.0/.

\section{References}

1. Stelter K. Tonsillitis and sore throat in children. GMS Curr Top Otorhinolaryngol Head Neck Surg. 2014. https://doi.org/10.3205/ cto000110.

2. Georgalas CC, Tolley NS, Narula A. Recurrent throat infections (tonsillitis). BMJ Clin Evid. 2007;2007:0503.

3. Eberechukwu YIL, Oluwajenyo AAT. A review of the pattern of malaria in children above neonatal age at the University of Port Harcourt Teaching Hospital (2006-2011). Univ J Clin Med. 2018;6(1):10-4. https://doi.org/10.13189/ujcm.2018.060102.

4. Adoga AA, Okwori ET, Yaro JP, Iduh AA. Pediatric otorhinolaryngology emergencies at the Jos University Teaching Hospital: study of frequency, management, and outcomes. Ann Afr Med. 2017;16(2):81-4.

5. Situation of women and children in Nigeria. Challenges faced by women and children in NigerialUNICEF Nigeria. http://www. unicef.org/nigeria/situation-women-and-children-nigeria.

6. Tesfaw G, Abdissa A. Prevalence of group A B haemolytic streptococcus among children with pharyngitis in Jimma town Southwest Ethiopia. Egypt J Ear Nose Throat Allied Sci. 2015;16(1):35-40.

7. Situation of women and children in Nigeria. Challenges faced by women and children in Nigeria. Accessed on October 29th, 2020. https://www.unicef.org.

8. Abraham ZS, Bazilio J, Kahinga AA, Manyahi J, Ntunaguzi D, Massawe ER. Prevalence and bacteriology of tonsillitis among patients attending otorhinolaryngology Department at Muhimbili 
National Hospital, Dar es Salaam Tanzania. Med J Zambia. 2019;46(1):33-40.

9. Torreta $\mathrm{S}$. The presence of biofilm-producing bacteria on tonsils is associated with increased exhaled nitric oxide levels: preliminary data in children who experience recurrent exacerbations of chronic tonsillitis. J LaryngolOtol. 2015;129(3):267-72.

10. Ajibola O, Omisakin OA, Eze AA, Omoleke SA. Self-medication with antibiotics, attitude and knowledge of antibiotic resistance among community residents and undergraduate students in Northwest Nigeria. Diseases. 2018;6(2):32. Published 2018 Apr 27. https://doi.org/10.3390/diseases6020032.

11. McIsaac W, Kellner J, Aufricht P, et al. Empirical validation of guidelines for the management of pharyngitis in children and adults. JAMA. 2004;291(13):1587-95.

12. Spinks A, Glasziou PP, Del Mar CB. Antibiotics for sore throat. Cochrane Database Syst Rev. 2013. https://doi.org/10.1002/14651 858.CD000023.pub4.

13. Venekamp RP, Sanders SL, Glasziou PP, et al. Antibiotics for acute otitis media in children. Cochrane Database Syst Rev. 2015. https://doi.org/10.1002/14651858.CD000219.pub4.

14. Keith T, Saxena S, Murray J, et al. Risk-benefit analysis of restricting antimicrobial prescribing in children: what do we really know? CurrOpin Infect Dis. 2010;23:242-8.

15. Uzochukwu BS, Onwujekwe EO, Onoka CA, Ughasoro MD. Rural-urban differences in maternal responses to childhood fever in south-East Nigeria. PLoS ONE. 2008;3(3):e1788. https://doi. org/10.1371/journal.pone.0001788.

16. Leupe P, Hox V, Debruyne F, Schrooten W, Claes NV, Lemkens N, Lemkens P. Tonsillectomy compared to acute tonsillitis in children: a comparison study of societal costs. B-ENT. 2012;8(2):103-11.

17. Duarte VM, McGrath CL, Shapiro NL, Bhattacharrya N. Healthcare costs of acute and chronic tonsillar conditions in the pediatric population in the United States. Int J PediatrOtorhinolayngol. 2015;79(6):921-5.

18. Chang JJ, Buchanan P, Geremakis C, Sheikh K, Mitchell RB, Metrics $P$. Cost analysis of tonsillectomy in children using Medicaid data. 2014; 164(6);1346-51(6):e1. https://doi.org/10.1016/j.peds. 2014.01.055

19. Wilson JA, Steen NI, Lock CA, Eccles MP, Carrie S, Clarke R, Kubba H, Raine CH, Zarod A, Bond J. Tonsillectomy: a costeffective option for childhood sore throat? Further analysis of a randomized controlled trial. Otolaryngol Head Neck Surg. 2012;146(1):122-8.

20. Gudnadottir G, Tennvall GR, Stalfors J, Hellgren J. Indirect costs related to caregivers' absence from work after paediatric tonsil surgery. Eur Arch Otorhinolaryngol. 2017;274:2629-36. https:// doi.org/10.1007/s0045-017-4526-7.

21. Roos KR, Claesson R, Persson U, Odegaard K. The economic cost of a streptococcal tonsillitis episode. Scand J Prim Health Care. 1995;13:257-60.

22. Suleiman IA, Tayo F. Evaluation of the cost of therapy in the management of ear, nose and throat infections in a Nigerian Teaching Hospital. Afr J Biomed Res. 2011;14:187-93.

23. Onwujekwe O. Moving from low coverage to universal health coverage: national health system challenges, equity and the evidencebase. In: 74th Inaugural lecture of the University of Nigeria, Enugu, Nigeria. https://doi.org/10.13140/RG.2.2.25811.99362.

24. Mwaura JW, Pongpanich S. Access to health care: the role of a community based health insurance in Kenya. Pan Afr Med J. 2012;12:35. https://doi.org/10.1160/pamj.2012.12.35.1704.

25. Onwujekwe O, Onoka C, Uguru N, Tasie N, Uzochukwu B, Eze S, Kirigia J, Petu A. Preferences for benefit packages for community-based health insurance: an exploratory study in Nigeria. BMC Health Serv Res. 2010;10:162. https://doi.org/10.1186/ 1472-6963-10-162.
26. Tabor SR. Community-based health insurance and social protection. In: Social protection discussion paper no 0503. World Bank, Washington, DC; 2005.

27. Thriemer K, Katuala Y, Batoko B, Alworonga JP, Devlieger $\mathrm{H}$, Van Geet C, Ngbonda D, Jacobs J. Antibiotic prescribing in DR Congo: a knowledge, attitude and practice survey among medical doctors and students. PLoS ONE. 2013;8(2):e55495.

28. Kimang'a AN. A situational analysis of antimicrobial drug resistance in Africa: are we losing the battle? Ethiop J Health Sci. 2012;22(2):135-43.

29. Enugu (State, Nigeria)—Population Statistics, Charts. https:// www.citypopulation.de/php/nigeria-admin.php? adm1id= NGA014. Assessed 27 Oct 2020.

30. Abia (State, Nigeria)-Population Statistics, Charts, Map and location. https://www.citypopulation,de/php/nigeria-admin. php?admilid. Assessed 27 Oct 2020.

31. Karigi AM. Construction of household asset based wealth index for eastern Region Kenya. A Research Project Submitted for Degree of Master of Science in Social Sciences. 2014.

32. Fan Z, Liu E, Xu B. Weighted principal component analysis. In: Deng H, Miao D, Lei J, Wang FL, editors. Artificial intelligence. AICI 2011. Lecture notes in computer science, vol. 7004. Berlin: Springer. https://doi.org/10.1007/978-3-642-23896-3_ 70.

33. Drummond MF, Sculpher MJ, Torrance GW, O'Brien BJ, Stoddart GL. Methods for the economic evaluation of health care programmes. 3rd ed. Oxford: Oxford University Press; 2005.

34. Ughasoro MD, Onwujekwe OE, Ojinnaka NC. Economic cost of treatment of childhood epilepsy in Enugu, Southeast Nigeria. Int J Technol Assess Health Care. 2014;30(4):469-74. https:// doi.org/10.1017/S0266-462314000518.

35. Chand S. Population density classification of the spatial distribution off population density. http://wwwyourarticlelibrary. com. Accessed 28 Jan 2019.

36. Maduka U, Joy E, Adaeze A, Uzoamaka A, Tagbo O. Economic cost of Treatment of childhood Asthma among children seen at follow up clinic in southeast Nigeria. PadiatrRespir Rev. 2020. https://doi.org/10.1016/j.prrv.2020.01.001.

37. Ke X, Jan K, Kei K, David E, Piya H, Juan O, Riadh Z, Christopher M (2003) Household Health System Contributions and Capacity to Pay: Definitional, Empirical, and Technical Challenges. Health systems performance assessment:debates, methods and empiricism. https://www.researchgate.net/publication/ 265497920_Household_Health_System_Contributions_and_ Capacity_to_Pay_Definitional_Empirical_and_Technical_Chall enges.

38. Statistics in Medicine. Statistical testing, risks and odds in medical decisions. In: Riffenburgh RH, editor. Statistics in medicine, 2nd edn. 2006. P. 581-4. https://doi.org/10.1016/ B978-0-12-088770-5.X5036-9.

39. Lupatsch JE, Kreis C, Korten I, Latzin P, Frey U, Kuehni CE, et al. Neighbourhood child population density as a proxy measure for exposure to respiratory infections in the first year of life: a validation study. PLoS ONE. 2018;13(9):e0203743. https:// doi.org/10.1371/journal.pone.0203743.

40. Jin J, Sklar GE, Oh VMS, Li SC. Factors affecting therapeutic compliance: a review from the patient's perspective. TherClin Risk Manag. 2008;4(1):269-86. https://doi.org/10.2147/tcrm. s1458

41. Gast A, Mathes T. Medication adherence influencing factors-an (updated) overview of systematic reviews. Syst Rev. 2019;8:112. https://doi.org/10.1186/s13643-019-1014-8.

42. Inkster ME, Donnan PT, MacDonald TM, Sullivan FM, Fahey T. Adherence to antihypertensive medication and association with patient and practice factors. J Hum Hypertens. 2006;20(4):295-7. 
43. Bond WS, Hussar DA. Detection methods and strategies for improving medication compliance. Am J Hosp Pharm. 1991;48(9):1978-88.

44. Svarstad BL, Shireman TI, Sweeney JK. Using drug claims data to assess the relationship of medication adherence with hospitalization and costs. PsychiatrServ. 2001;52(6):805-11.

45. Tsevat J, Kotagal UR. Management of sore throats in children: a cost effectiveness analysis. Arch PediatrAdolesc Med. 1999;153(7):681-8. https://doi.org/10.1001/archpedi.153.7.681.

46. Cleopatra I, Eunice K, Household catastrophic health expenditure: evidence from Nigeria. Microeconomics and Macroeconomics. 2018;6(1):1-8. https://doi.org/10.5923/j.m2economics.20180601. 01.

47. Xu K, Evans D, Kawabata K, et al. Household catastrophic health expenditure: a multi-country analysis. Lancet. 2003;362:111-7.

48. Monye FN. An appraisal of the national health insurance scheme of Nigeria. Commonw Law Bull. 2006;32:415-22.
49. Organization of African Unity (OAU). Abuja declaration on HIV/ AIDS, tuberculosis, and other related infectious diseases. Abuja: OAU; 2001.

50. Ebunoha GN, Ughasoro MD, Nwakoby IC, Onwujekwe OE. Achieving financial risk protection through a national Social Health Insurance Programme in Nigeria: Perspectives of enrollees and healthcare providers. Int J Health Plan Manag. 2019. https:// doi.org/10.1002/hpm.2949.

51. WHO. Health financing strategy for Asia Pacific region 2010 2015.Geneva: WHO; 2009.

52. Xu K, Evans DB, Carrin G, Aguilar-Rivera AM. Designing health financing systems to reduce catastrophic health expenditure. Technical Briefs for Policy Makers no. 2 Geneva: World Health Organization; 2005. 